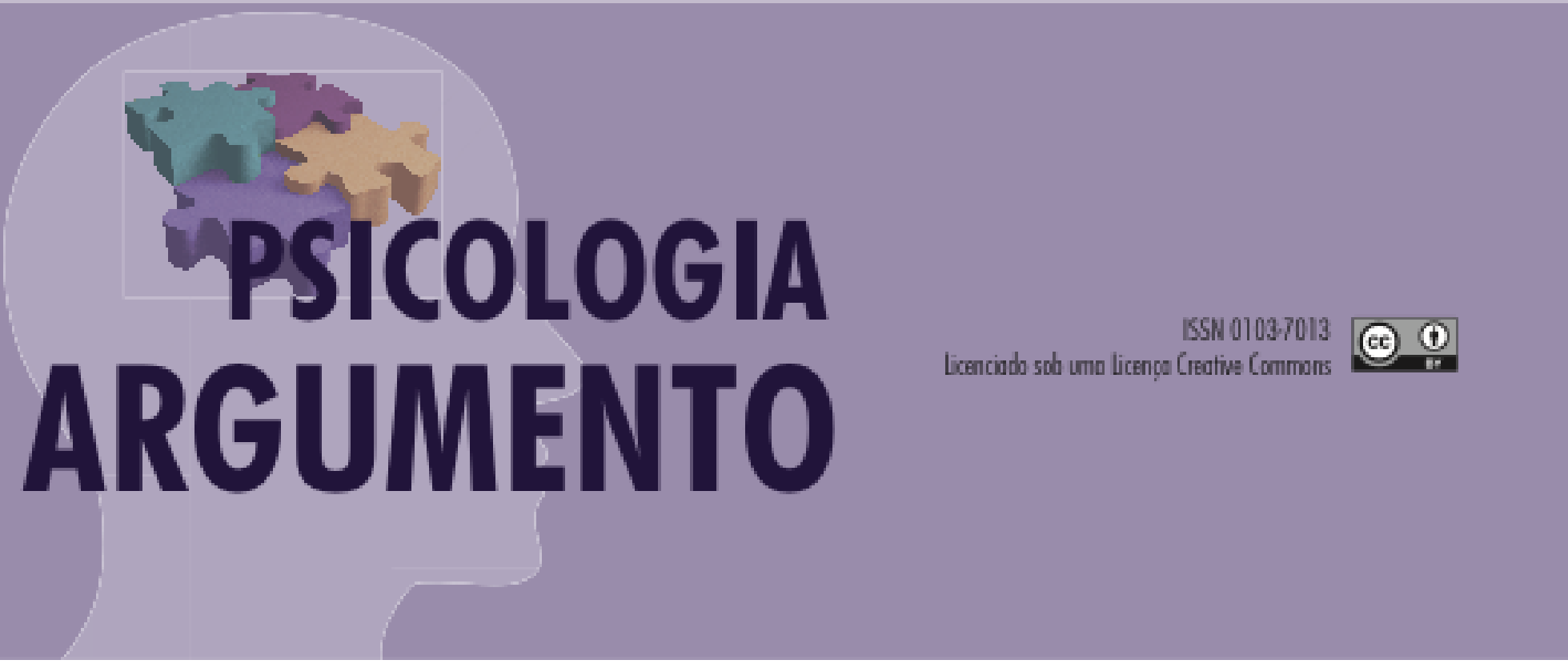

doi $10.7213 /$ psicol.argum.33.082.AO05

\title{
De algozes a vítimas: dos direitos cegos e nulos à mulher gestante em situação de cárcere.
}

\author{
Perpetrators to victims: the blind and void rights of pregnant \\ woman in jail situation.
}

Eliane Aparecida Calhiari [a], Leticia Rodrigues da Silva Santos [b], Bárbara Cossetin Costa Beber Brunini[c]

[a] Acadêmica. Universidade Paranaense - Unipar. Umuarama. eliane_calhiari@hotmail.com

${ }^{[b]}$ Acadêmica. Universidade Paranaense - Unipar. Umuarama. le_rodrigues_s@live.com

[c] Docente. Universidade Paranaense - Unipar. Umuarama

barbrunini@unipar.br

\section{Resumo}

Este artigo problematiza os ambientes carcerários como instituições totais e de disciplinamento dos corpos, independente do gênero a que se destina. Faz-se uma crítica à falência das instituições carcerárias que deixaram há muito tempo de exercer seu papel fundamental, o de "ressocialização dos sujeitos". Os métodos utilizados para imposição do poder naturalizam expressões e formas de estar no mundo, inviabilizando corpos que se permitem romper as fronteiras territoriais do sistema empobrecido binário que reduzem as possibilidades humanas. Tem-se uma atenção especial ao corpo feminino que ao movimentar-se entre as fronteiras passa a sofrer processos de exclusão, a partir do momento em que rompe com as normas impostas ao gênero feminino. Os estigmas aumentam quando esse corpo está em 
situação de cárcere em período gestacional e de amamentação. Cabe ao profissional Psi um posicionar-se criticamente e com estratégias que possibilite o empoderamento dessas mulheres em conhecer seus direitos, denunciando a negligência que o sistema comete com as mulheres em situação de cárcere. Através da pesquisa bibliográfica e documental, este trabalho pretende ser um convite a problematização do corpo feminino gestante em cárcere bem como a ausência daqueles direitos humanos ditos por lei direitos adquiridos.

$[\mathrm{P}]$

Palavras-chave: Sistema prisional; mulher gestante; políticas de direitos.

\begin{abstract}
This article discusses the prison environment as total institutions and disciplining of bodies, regardless of gender to which they relate. It should be a critique of the failure of prison institutions that have left a long time to exert their fundamental role, the "rehabilitation of the subjects." The methods used to power the imposition naturalize expressions and ways of being in the world, ruling bodies that allow break the territorial torque impoverished system boundaries that reduce human possibilities. It has been a special attention to female body to move between the borders starts to suffer exclusion processes, from the moment that breaks with the standards imposed on females. The stigmas increase when the body is the prison situation in pregnancy and breastfeeding. It is for the professional Psi one position itself critically and strategies that enable the empowerment of these women to know their rights, denouncing the neglect that the system commits to women in prison situation. Through bibliographical and documentary research, this work is intended as an invitation to questioning the female pregnant body in prison and the absence of those so-called human rights by law vested rights. [
\end{abstract}

$\mathrm{K}]$

Keywords: prison system; pregnant women; rights policies.

\title{
Problematizando
}

A análise da presente pesquisa permeia ambientes ora não desejados para o contexto de reflexão social. Apesar de ser nítida a necessidade de uma atenção voltada aos corpos diferentes, ou da exclusão, parece estranho ainda hoje, pensar em sujeitos submetidos às estruturas arquitetônicas que refletem em nossa sociedade contemporânea, características de um sistema da soberania, comprometido com o seu dever de punir todo e qualquer corpo da transgressão, da desordem, do desequilíbrio e da anormalidade.

Ao se refletir sobre a possibilidade de pesquisar e escrever sobre a mulher gestante em ambiente de cárcere, depara-se, inicialmente, com provocações de qual seria este ambiente, que espaço ocupa na sociedade, e em que espaço segrega e guarda os sujeitos de sua intenção.

Tais espaços celulares são denominados por Goffman (1987) (prisões, manicômios e conventos) como instituições totais, e por Foucault (2004) como instituições disciplinares, locais os quais o sujeito permanece, durante um determinado tempo, e nele realiza todas as suas atividades, sejam essas impostas por um sistema hierárquico que o insere ao meio, por exemplo, estabelecimentos prisionais, hospitalares, manicomiais ou por vontade do próprio sujeito, quando aceita ser um corpo assujeitado por supostos ganhos afetivos nestes recintos, como escolas, conventos e seminários.

Pensar nesses estabelecimentos como locais de acolhimento não se faz tarefa fácil, nem mesmo prazerosa, quando o público usuário dele é o corpo feminino e gestante. Aqui, depara-se com situações perpassadas por preconceitos e estigmas os quais impedem a leitura esperada de um conjunto de direitos oferecidos à mulher gestante em situação de cárcere, bem como a fragilidade de políticas públicas que deveriam beneficiar este corpo de cuidado necessário e direito adquirido. 
Frente a um vasto conjunto de determinações, leis e resoluções sobre o direito e os cuidados da mulher gestante em situação de cárcere, foi realizado uma breve pesquisa documental que viesse ao encontro de nossas indagações. Documentos produzidos com seriedade e beleza, todavia, nem sempre vivenciados por aquele que realmente dele deveria usufruir.

Igualmente é interesse do presente estudo, o levantamento bibliográfico que pudesse alimentar teoricamente os nossos ensaios sobre o tema pesquisado, como também que fortalecem o nosso fazer Psi frente esta usuária. O desassossego por nós experimentado diante dessa problemática, nos fez refletir sobre o que, como e quando tais políticas públicas se fazem eficientes nestes espaços e como nós, profissionais da Psicologia, estamos respondendo a esta demanda ao sermos solicitados como corpo de saber científico por órgãos de poder como Ministério Público, as ações sociais, e o nosso próprio Conselho de Ética.

\section{O estabelecimento penitenciário como espaço falido de atenção ao corpo gestante}

Quando referenciamos as instituições carcerárias, espaço de nossas reflexões neste trabalho, as visualizamos como instituições totais, termo este descrito por Goffman (1987) para identificar espaços que provocam a ruptura total com o cotidiano e com o meio social anteriormente vivenciado pelo sujeito, produzindo um desculturamento e mortificação do próprio "eu", mediante rebaixamentos, estigmas e humilhações.

Neste espaço os sujeitos são assujeitados à estrutura arquitetônica, disciplinar e de correção ou modelagem, realizam suas atividades cotidianas sob o olhar atento daquele que é dotado do status de cuidar, educar, curar, punir, produzir. Ao se afirmar a existência de instituições totais, pode-se perceber que existem diversas tendências que as caracterizam e as diferenciam, pois segundo Goffman (1987, citado por Foucault, 2004) toda instituição total possui tendência ao "fechamento", mas uma mais que as outras. Prisões, hospitais, manicômios, conventos, colégios internos, todos estes podem consideradas instituições totais.

Dentro dessas instituições são priorizadas relações marcadas por um poder hierárquico verticalizado, por vezes opressor, que exige do sujeito formas disciplinares e normatizadas de pensar e fazer, outras vezes produtivo, quando conduz os corpos pelas tecnologias políticas. Conforme Foucault (2004), essas tecnologias são mecanismos que controlam os corpos no intuito de manter a eminência da punição, capaz de manejar o espaço, o tempo e normas, marcando-os pela condição de privação, detenção e vigilância, mas também de corpo de serviço de produção.

A prisão, na presente pesquisa, também é entendida como uma instituição disciplinar, que poderá ser, de acordo com as contribuições foucaultianas, considerada aparelho fundamental em relação à correção de sujeitos que não se enquadram na sociedade civilizada e associada aos mecanismos próprios utilizados pela disciplina que produzem corpos dóceis e úteis por meio da privação de liberdade, numa ortopedia do comportamento objetivada à recuperação dos indivíduos pervertidos.

Quando escrevemos sobre intuições totais, mais precisamente a carceragem, devemos ter clara a existência de ambientes de ambos os gêneros. Sabe-se que nestes espaços perpassam os mesmos processos de disciplinamentos que de acordo a teoria foucaultiana almejam a docilização e correção, servindo como aparelho para transformar 
os indivíduos em sujeitos assujeitados as microfísicas deste poder. De acordo com Coimbra, Lobo e Nascimento (2009), sujeitos assujeitados, são aqueles que se reduzem e se deixam moldar pelas restrições e normas impostas pelas instituições.

Segundo Foucault (2004) a prisão possui três características centrais de ação sobre o sujeito apresentadas como: o isolamento, o trabalho e o instrumento de modulação da pena. O isolamento possui característica principal, um confinamento individual e individualizante que evita conflitos com outros sujeitos e possíveis influências, promovendo a submissão total ao sistema, com a intenção de fazer com que o sujeito reflita sobre seu ato considerado judicialmente delituoso, originando o remorso sobre a conduta não esperada.

O trabalho é caracterizado como contribuição do apenado ao sistema carcerário que o recolhe. Este corpo que produz contribui, mas pode ser recompensado pelo seu trabalho quando a uma leitura de seu esforço. Se a leitura o conceituar como "boa conduta carcerária", o apenado passa por uma mudança "positiva" do regime da pena.

Os instrumentos de modulação de pena, visualizados na tipificação do delito, nos regimes de condenação, nas formas de julgamento, e em atividades tão descritas por Foucault quando em 'Vigiar e Punir' (2004) escreve sobre o inquérito e o exame.

Foucault (2004) entende como inquérito aquele mecanismo privilegiado capaz de produzir verdades, possuindo como base uma pesquisa autoritária de uma verdade a fim de constatação dos fatos, tendo uma origem na soberania monárquica e no poder religioso. E sobre o exame o autor escreve:

O exame combina as técnicas da hierarquia que vigia e as sanções que normaliza. É um controle normalizante, uma vigilância que permite qualificar, classificar e punir. Estabelece sobre os indivíduos uma visibilidade através da qual eles são diferenciados e sancionados (Foucault, 2004, p. 154).

Este é considerado peça essencial na reprodução do poder, pois é capaz de reconduzir o disciplinamento daqueles indivíduos visualizados transgressores, por meio de rituais.

O mesmo autor afirma que a "superposição das relações de poder e das de saber assume no exame todo o seu brilho visível" (Foucault, 2004, p. 154), possuindo um mecanismo capaz de descrever, mensurar, ajustar e comparar a outros em sua própria singularidade. O exame também possui poder de treinar, classificar, normalizar e de excluir. "Finalmente o exame está no centro dos processos que constituem o indivíduo como efeito e objeto do poder. É ele que, combinando vigilância hierárquica e sanção normalizadora, realiza as grandes funções disciplinares de repartição e classificação" (Foucault, 2004, p. 160).

Ao referenciar a vigilância, fator marcante nos espaços prisionais, Foucault (2004), a considera como uma estratégia de olhar, um mecanismo de controle, sempre acompanhada de sanções que buscam normalizar. Tem uma eficácia ao conseguir adentrar o comportamento dos homens. "De modo que não é necessário recorrer à força para obrigar o condenado ao bom comportamento, o louco à calma, o operário ao trabalho" (Foucault, 2004, p. 167).

A vigilância pode ser considerada como um dispositivo que por meio das técnicas do olhar induzem a efeitos de poder. É decisiva por ser ao mesmo tempo: “[...], uma peça 
interna no aparelho de produção e uma engrenagem específica do poder disciplinar" (Foucault, 2004, p. 147). Os processos de vigilância acontecem por outros mecanismos identificados nas prisões, como o controle dos espaços, os horários, as imposições para visitas, o recebimento de encomendas de fora dos portões prisionais, entre outros. Nada muito diferente dos processos disciplinares, mesmo porque a vigilância se faz um de seus dispositivos.

Uma combinação entre a vigilância e as sanções normalizadoras do exame faz com que sejam evitados eventuais comportamentos indesejados utilizando-se de correções. $\mathrm{Na}$ essência de todos os sistemas disciplinares, funciona um pequeno mecanismo penal. As sanções normalizadoras são capazes de estabelecer dentro de uma lacuna deixada pela lei, medidas que punem, rebaixam, qualificam e reprimem comportamentos que escapam aos grandes sistemas de castigos. "Trata-se ao mesmo tempo de tornar penalizáveis as frações mais tênues de conduta e de dar uma função punitiva aos elementos aparentemente indiferentes ao aparelho disciplinar; levando ao extremo, que tudo possa servir para punir a mínima coisa" (Foucault, 2004, p. 149).

Em ambiente prisional, as relações de poder podem ser vistas em qualquer tipo de contato, lembrando que quando Foucault (1982) descreve sobre o poder, não o localiza em uma pessoa, instituição ou posição, mas sim nestas relações que se produzem dele. Nessa perspectiva, o estudioso defende a ideia de que o poder não é um objeto, uma coisa, mas relações de poder que atravessam toda a sociedade produzindo verdades a partir de coerções para os subordinados.

O que é fascinante nas prisões é que nelas o poder não se esconde não se mascara cinicamente, se mostra como tirania levada aos mais íntimos detalhes, e, ao mesmo tempo, é puro, é inteiramente "justificado", visto que pode inteiramente se formular no interior de uma moral que serve de adorno a seu exercício: sua tirania brutal aparece então como dominação serena do Bem sobre o Mal, da ordem sobre a desordem (Foucault, 1982, p. 73).

As conversações e os discursos efeitos dessas relações se fazem somente de forma verticalizada e hierarquizada embutindo a ideia de subalternidade, respeito e disciplinamento em que o trabalho é considerado um instrumento de transformação de sujeitos infratores, qualificando-os para desempenhar seu papel de produção com harmonia.

Segundo Foucault (1997) ao pensar nos processos disciplinadores dentro de instituições totais como os ambientes carcerários, os sujeitos tornam-se objetos de investigação e para investigar este dispositivo da disciplina foi criado o método do exame.

"Sabe-se que a disciplina aumenta a força dos corpos (em termos econômicos de utilidade), e diminui essas mesmas forças (em termos políticos de obediência) " (Foucault, 2004, p. 119). Aparentemente, mais uma forma de constatação do provável retrocesso do modelo de punição de julgamento do ato acompanhado do suplício dos corpos, agora, representado não pelo castigo do soberano, mas pelo poder da Lei e da sobrevivência em ambiente de cárcere.

Mesmo com a mudança dos regimes de punição e da legalização da tipificação dos delitos, este corpo ainda se faz supliciado quando constatado o número elevado de apenados em espaços insalubres, a alimentação e higiene não satisfatórias. Esses 
ambientes expressa nos corpos sofrimento, que além de ferir a integridade física, também fere a integridade psíquica.

No Brasil, essas instituições são reconhecidas como espaços "falidos" deste seu surgimento, por serem classificados como espaços de depósitos humanos que não oferecem condições de dignidade para os sujeitos, embora seja esse direito é inerente a todos como previsto nos Princípios Fundamentais da Constituição da República Federativa do Brasil (promulgada em 1988), segundo a qual o Brasil "constitui-se em Estado democrático de direito e tem como fundamentos: I - a soberania; II - a cidadania; III - a dignidade da pessoa humana".

$\mathrm{Na}$ contemporaneidade, as intuições disciplinares/totais, mantém sua finalidade de fixar os indivíduos à normatização visando à produtividade muda, aquela que produz sem questionar e problematizar. As disciplinas presentes nos ambientes carcerários fazem com que os sujeitos redesenhem sua forma de estar no mundo de acordo com os discursos de verdade ali instituídos. Foucault (1982), explica que nos discursos de verdade, podem ser percebidas relações constituídas de poder com capacidade de aprisionar os indivíduos:

A verdade é deste mundo; ela é produzida nele graças a múltiplas coerções e nele produz efeitos regulamentados de poder. Cada sociedade tem seu regime de verdade, sua "política geral" de verdade, isto é, os tipos de discurso que aceita e faz funcionar como verdadeiros..., os meios pelo qual cada um deles é sancionado, as técnicas e procedimentos valorizados na aquisição da verdade (p. 12).

Ele continua afirmando que, a verdade está ligada intrinsecamente ao sistema de poder sendo considerada, um conjunto de procedimentos regulados para a produção da lei. Comenta ainda que utilizar-se de um bom discurso significa dominar e controlar as pessoas e direcionar sua história, representando interesses de classes. Esses fatores são moldados e movimentados por uma ideologia capitalista que acaba sendo responsável pelo controle social e elaboração dos conceitos de verdade por meio de normas concretizadas, as quais emergem das relações presentes nos jogos de poder-saber.

De acordo com Miyamoto e Krohling (2012) essa ideologia de exclusão capitalista reflete diretamente no sistema prisional, que "de fato, é o registro da marca da desigualdade social uma vez que os indivíduos que são presos são exatamente aqueles que já sofrem o processo de exclusão social" (p. 230).

Vale ratificar que a mortificação dos corpos acontece não apenas dentro dos estabelecimentos penitenciários, mas estende-se as outras instituições totais que constituem a sociedade, promovendo desigualdade e exclusão que refletem no aumento do índice da violência.

Os sistemas penitenciários nacionais possuem como objetivos principais a educação, punição do delito e a ressocialização, mas acabam apenas adotando uma postura rígida e punitiva que desfavorece o cumprimento de seus demais objetivos, acarretando assim a reincidência dos presos e presas. Espinoza (2004) afirma que essa reincidência também é reflexa da atividade precária existente dentro dessas instituições que acaba dificultando a inserção do egresso no mercado de trabalho, favorecendo, por vezes, a reincidência ao crime.

Por mais que essa realidade esteja presente em estabelecimentos prisionais masculinos e femininos, nestes últimos, além da exclusão sofrida pelo estigma da prisão, a 
mulher inserida no sistema carcerário brasileiro, passa também por estigmas e preconceitos do tradicionalista sistema patriarcal, que se caracteriza por acentuar as desigualdades sociais e o poder diferenciado do gênero masculino em relação ao feminino.

De acordo com Saffioti (1997), sistema patriarcal pode ser entendido como um conjunto de relações sociais os quais os homens possuem hierarquicamente o poder de controlar e oprimir as mulheres. Ele possui princípios evidentes que são os que dividem as mulheres em duas categorias as boas e as ruins, no caso da última a elas cabe a violência e a punição e também elas são consideradas como propriedade dos homens. Assim, são percebidas as influências do patriarcado que perpassam a sociedade que se esforça em preservar e garantir a supremacia do gênero masculino.

\section{A leitura do gênero feminino}

Ao longo da história das sociedades as diferenças anatômicas dos órgãos sexuais femininos e masculinos foram determinantes na naturalização de papéis instaurados a homens e mulheres. A partir de 1960, iniciou-se uma desconstrução dessa biologização com a formulação dos estudos de gênero. Como escreve Butler (2010, p. 143) gênero pode ser compreendido como "um modo contemporâneo de organizar normas passadas e futuras, um modo de nos situarmos e através dessas normas, um estilo ativo de viver nosso corpo no mundo". Estar homem e estar mulher são entendidos nas perspectivas de gênero como situações produzidas e reproduzidas e/ou transformadas ao longo do tempo. No entanto, o que se deve considerar, é que esses aprendizados objetivam propiciar não somente formas de feminilidade e masculinidade, mas compreender as complexas redes de poder envolvidas na construção de hierarquias.

As algemas da natureza do destino biológico produzem um olhar essencialista de gênero que se caracteriza por propriedades estáveis e inatas com um caráter determinista o qual inviabiliza outras formas de estar no mundo. Há de se considerar outra perspectiva de gênero, a da construção. Esta é compreendida como um resultado de forças sociais e culturais passando por um processo de aprendizagens a partir da socialização (Borges, Canuto, Oliveira, Vaz, 2013). De acordo como os autores supracitados, ao se afirmar que gênero deve ser considerado uma construção, há a necessidade de posicionamentos contrários diante da naturalização imposta pelos determinantes biológicos que fixam o ser feminino e o ser masculino.

Foucault (1988), também traz contribuições que enriquecem a perspectiva de gênero como construção quando diz que a sexualidade é construída num processo sócio histórico a partir das relações estabelecidas que possibilitem diferentes formas de identidades de gênero e sexuais. Louro (1997) afirma que existe um processo de construção dos gêneros e das sexualidades que acontece de uma forma sutil, podendo ser apontado como instâncias importantes nesse processo: a família, escola, igreja, instituições legais e médicas por meio de inúmeras aprendizagens de formas explícitas ou de formas sutis a ponto de não serem percebidas passando por constantes transformações.

Louro (1997) escreve que é preciso evitar teorias que essencializem o gênero, dirigindo-se por um processo de construção e não para algo a priori. Sendo assim, a teórica passa a exigir afirmações que levem em consideração múltiplas formas de estar no mundo, permeados por diversos momentos históricos e culturais em uma sociedade composta de diversos grupos tais como étnicos, religiosos, raciais e de classe. 
A autora supracitada continua a esclarecer que as afirmações que levam em consideração o conceito de gênero como uma construção histórica social, não devem se reduzir somente à construção de papéis masculinos e femininos, pois papéis têm ligações com padrões pré-instituídos por uma sociedade que possui um poder de definição de comportamentos, com características tais como, mulher carinhosa, meiga, boa mãe, boa esposa, moça de família, chefe de casa, próprios da sociedade sexista, machista e patriarcal.

Defende que as transformações aceleradas na sociedade produzem novos saberes, novas formas de relaciona-se e de posicionar-se, evidenciando a afetação em campos até então imutáveis e universais. Ao se adentrar o terreno dos gêneros e da sexualidade deve ter claro que um dos grandes desafios é: "[...] admitir que as fronteiras sexuais e de gênero vêm sendo constantemente atravessadas e o que é ainda mais complicado admitir que o lugar social no qual alguns sujeitos vivem é exatamente a fronteira" (Louro, 2004, p.28), como corpos nômades.

Para Deleuze e Guatarri (1995), existem duas linhas segmentares que são a molar e a molecular. As características da linha molar equiparam-se a rigidez vivenciada pelos corpos que são atravessados por discursos enrijecidos que limitam o estar no mundo, pois são impedidos de ultrapassarem o binarismo imposto.

Judith Butler (2010), cita esse binarismo como um sistema empobrecido de: sexo/gênero/desejo/práticas sexuais, na perspectiva da autora esse sistema binário é imposto pela força dos discursos que desconsidera as construções culturais, impossibilitando outras formas de estar além das impostas por acreditar que práticas sexuais, sexualidade e gênero são naturalizados, aculturados. A autora afirma "a rigor, talvez o sexo sempre tenha sido gênero, de tal forma que a distinção entre sexo e gênero revela-se absolutamente nenhuma" (Butler, 2010, p. 25).

A linha molecular segundo Deleuze e Guattari (1995), pode ser entendida como um corpo nômade em constante movimento em que as micropolíticas querem criar, inovar e ampliar seus territórios estando em constante desterritorialização que proporcionará novas experiências e acabará produzindo novos conhecimentos. Nômades para Deluze e Guatarri (1996), não são forçadamente corpos que se movimentam como migrantes, mas sim corpos que se permitem viajar num mesmo território de forma intensa nomadizando-se para escapar dos códigos normatizados. "E mesmo se a viagem for imóvel, mesmo se for feita no mesmo lugar, imperceptível, inesperada, subterrânea devemos perguntar quais são os nômades de hoje" (Deleuze, Guatari, 1996, p. 328). Ser nômade é movimentar-se a serviço da resistência, possibilitando desloca-se em múltiplas experimentações.

Os movimentos feministas potencializam as mulheres a fim de se construírem corpos nômades, corpos que resistem as imposições rígidas de molaridade, que lutam contra os valores tradicionais e conservadores, decorrente por uma ideologia machista e sexista. Corpos desejantes e criativos que ao movimentar-se contra os discursos prontos em territórios habitados por corpos disciplinados são colocados na fronteira social.

Foucault $(1988 ; 1984 ; 1985)$ ao construir a trilogia da História da Sexualidade, abordou aquilo que se era esperado de cada um, e, como a transição e as mudanças sócio históricas também modificaram os discursos impostos a construção identitária dos deveres de cada gênero, desconstruindo, assim, a ideia contemporânea de gênero como essência e reforçando a ideia de algo construído através das mais diversas instituições disciplinares e totais. 
Badinter (1985) escreve que é possível descontruir, afirmativas as quais tornam esses comportamentos deterministas, como o mito do amor materno, produto o qual pode perceber sua construção ao longo das transformações regidas pelas constantes modificações socioeconômicas. Dessa forma, é possível compreender a dificuldade em aceitar a maternidade em cárcere como realidade institucional e não instintual.

De acordo com as autoras Miyamoto e Krohling (2012) se a função básica da prisão é a punição, a mulher acaba sendo então punida duas vezes. Primeiro por cometer o crime, e segundo por não cumprir seu papel social de passividade e conformação com seu espaço social.

\section{Legislações e resoluções sobre os direitos da mulher}

As relações desiguais de gênero mantêm-se dentro do sistema prisional brasileiro o qual favorece inúmeros estigmas para a mulher que se encontra nessas instituições. Os estigmas aumentam quando essa mulher encarcerada encontra-se no período gestacional e de amamentação. Em respeito a essa condição dos corpos em cárcere, a Constituição Federal Brasileira de 1988, alerta em seu Art. $5^{\circ}$ (caput) que:

Todos são iguais perante a lei, sem distinção de qualquer natureza, garantindo-se aos brasileiros e aos estrangeiros residentes no País a inviolabilidade do direito à vida, à liberdade, à igualdade, à segurança e à propriedade, nos termos seguintes:

I: homens e mulheres são iguais em direitos e obrigações, nos termos desta Constituição;

Art. $5^{\circ}$-XLVIII: a pena será cumprida em estabelecimentos distintos, de acordo com a natureza do delito, a idade e o sexo do apenado;

Art. $5^{\circ} \mathrm{L}$ - às presidiárias serão asseguradas condições para que possam permanecer com seus filhos durante o período de amamentação.

A Lei de Execução Penal (lei 7.210/84) traz algumas especificidades sobre o direito da mulher presa, garante que " $\S 2^{\circ}$ Os estabelecimentos penais destinados a mulheres serão dotados de berçário, onde as condenadas possam cuidar de seus filhos, inclusive amamentá-los, no mínimo, até 6 (seis) meses de idade". Em observância a esses direitos, deveriam ser garantidos aspectos que proporcionassem condições harmônicas de uma integração social da encarcerada em processo de gestação.

No Plano Nacional de Saúde no Sistema Prisional -PNSSP (2004), é expressa a garantia que a mulher presa tem de atendimento à saúde pública, incluindo o controle do câncer cérvico uterino e de mama e, não menos importante, o acompanhamento pré-natal quando gestantes, direito esse, destinado a todas as mulheres brasileiras, independentemente de sua situação econômica, psicológica, social ou legal.

Dentre essas, existem outras garantias especificadas no PNSSP (2004) como por exemplo, a implantação da imunização das gestantes, a implantação ao puerpério e ações educativas sobre pré-natal, parto, puerpério, anticoncepção e atendimentos diante de intercorrências e parto. Mas, apesar dessas metas e objetivos propostos pelo PNSSP, dos artigos previstos na Constituição Federal Brasileira e na Lei de Execução Penal, é possível identificar o descaso no não cumprimento dessas instituições diante da população feminina em qualquer ambiente prisional onde ela estiver cumprindo a pena, o que em diversas situações, acontece mesmo sem que essa mulher tenha sido julgada ou informada de seu processo condenatório. 
Outro documento/lei que identifica e qualifica o direito de gestantes em cárcere é o Estatuto da Criança e do Adolescente - ECA (2012) o qual, em seus Art. $8^{\circ}$ e $9^{\circ}$, preconiza o atendimento especializado pré e perinatal as mulheres por uma equipe multidisciplinar que garantam o bem-estar da criança e da mãe, não fazendo restrição as mulheres que estejam em privação de liberdade.

Cabe ao poder público o dever de "proporcionar assistência psicológica à gestante $\mathrm{e}$ à mãe, no período pré e pós-natal, inclusive como forma de prevenir ou minorar as consequências do estado puerperal" (Lei ${ }^{0}$ 8.069/90, de Julho de 1990, p. 16). Os profissionais Psi que adentrem as instituições penitenciárias devem engajar-se em garantir a potencialização dos direitos das mulheres, muitas vezes aviltada por um sistema opressor. O Conselho Federal de Psicologia em sua resolução no 009/2010, delibera que os profissionais de Psicologia, em suas práticas no Sistema Prisional, deverão promover os direitos humanos, a construção da cidadania, em busca de uma desconstrução dos discursos que o culpabilizam e desconsidera os dispositivos sociais que o atravessam e produzem o processo de criminalização.

Os Psicólogos devem trabalhar na construção de estratégias que busquem fortalecer os vínculos sociais, resgatando a cidadania e possibilitando as mulheres encarceradas inserção com a sociedade extramuros. Dentro das práticas Psi cabe compreender essas mulheres em sua totalidade, considerando todas as linhas que as atravessam e constroem o seu processo de subjetivação.

\section{Dos Direitos cegos e nulos à maternidade da mulher encarcerada}

Ao se perceber a discriminação pautada em relações estigmatizadas que perpassam o gênero ocasionando inúmeras violações, inclusive do Estado, é necessário que se compreenda que maternidade em situação de cárcere deve ser pensada com uma postura crítica. Na Cartilha da Mulher Presa publicada pelo Conselho Nacional de Justiça (2011) são elencados vários direitos garantidos considerados fundamentais, até mesmo expressos na Constituição Federal desde 1988, não fazendo distinção de raça, sexo, cor, idade, língua, opinião política ou quaisquer outras formas de discriminação. Também é garantida a essas mulheres a proibição de qualquer forma de violência física, moral e psíquica nestes estabelecimentos, como em qualquer outro.

Quanto ao espaço físico, a Cartilha da Mulher Presa (2011), enfatiza que sejam espaços distintos àqueles destinados aos homens e a segurança desses espaços femininos deverá ser realizada por agentes do sexo feminino. A mulher em situação de cárcere "tem direito à assistência à saúde, respeitadas as peculiaridades da sua condição feminina" (Conselho Nacional de Justiça, 2011, p. 12). Tem direito a uma política de saúde preventiva e também a continuidade de tratamentos já inicializados anteriormente. Quando necessário, poderá ser solicitado à assistência de várias especialidades médicas e também a acompanhamentos de profissionais Psi.

Com a possibilidade de problematizar o direito à dignidade percebem-se discursos muito bem elaborados, mas discrepantes e vazios quando vivenciados. As mulheres em situação de cárcere, sofrem no corpo o mascaramento de seus direitos que são colocados em segundo plano. Essas mulheres possuem seus direitos violados, vivenciam a revitimização do processo de exclusão e estigmatização do qual já vivenciaram socialmente pelas diversas linhas de atravessamento. Uma dessas violências que dão início a vida em cárcere é a quebra de uma das condições mínimas de reconhecimento social, o 
direito de ser tratada pelo nome, respeitado sua subjetividade e não as enquadrando a violações que cometeram.

As prisões dentro do cenário brasileiro descumprem seu papel de ressocialização e empoderamento das mulheres em situação de cárcere, ao reduzir-se a uma instituição total, com discursos verticalizados que enfatizam deveres a serem cumpridos, tais como: "Você deve ter comportamento disciplinado e dar fiel cumprimento à sentença. Também deve obediência" (Conselho Nacional de Justiça, 2011, p. 16). Observa-se, uma inoperância na lei favorecendo aviltamentos dos direitos humanos a qual limita as possibilidades.

Ao se pensar na mulher em situação de cárcere, grávida ou em período puerperal, é necessário refletir as fronteiras visíveis e invisíveis que são limitadas pela realidade prisional. Rita (2006), denuncia as discordâncias que ocorrem, apontando que, em muitas unidades prisionais os filhos permanecem junto com a mãe e outras apenadas, ferindo um direito que prevê que mãe e filho devem ter espaços próprios, tais como berçários e creches.

A Lei n. 11.942/2009 em sua nova redação assegura em seus artigos 83 e 89 da Lei de Execução Penal, artigos estes nos quais se lê que as mulheres em situação de cárcere possuem o direito de cuidar e amamentar seus filhos por, no mínimo, seis meses, prevendo ainda que as penitenciárias de mulheres deverão obrigatoriamente dispor de espaços adequados ao acolhimento de gestantes e parturientes: "Art. 83. $\S 2^{\circ}$. Os estabelecimentos penais destinados a mulheres serão dotados de berçário, onde as condenadas possam cuidar de seus filhos, inclusive amamentá-los, no mínimo, até 6 (seis) meses de idade" (2009, p. 1). Nesta mesma lei preconiza-se que

Art. 89. Além dos requisitos referidos no art. 88, a penitenciária de mulheres será dotada de seção para gestante e parturiente e de creche para abrigar crianças maiores de 6 (seis) meses e menores de 7 (sete) anos, com a finalidade de assistir a criança desamparada cuja responsável estiver presa (Lei n. 11.942, 2009, p.1).

Rita (2006) aponta discordâncias na efetivação da lei pelos gestores prisionais para a definição do tempo que a criança permanece com a mãe e denuncia que quanto à atenção médica "os profissionais destinados aos atendimentos das mães e crianças, além de insuficientes numericamente, não são das áreas específicas como ginecologia e pediatria, nutrição e educação infantil" (Rita, 2006, p. 150). Ormeño (2013) ao citar a Lei 8069/90 discorre que:

Após o parto, a presa tem o direito de permanecer em uma unidade prisional para atendimento e acompanhamento do bebê, e se caso não houver vagas em unidades prisionais com berçário, é possível, pela intermediação de um advogado ou Defensor Público, solicitar ao juiz seis meses de prisão domiciliar. Além disso, o poder público deve proporcionar assistência psicológica à gestante e à mãe, no período pré e pós-natal, inclusive como forma de prevenir ou minorar as consequências do estado puerperal (Ormeño, 2013, p. 168).

O período pré-natal e pós-natal dentro do cárcere envolve uma série de conflitos a essas mulheres. Rita (2006) esclarece que a mulher nessa situação vivencia constantes quebras de vínculos familiares, e a retirada de seu filho pode ser considerada uma das 
piores perdas, uma dupla penalização, entretanto, elas mesmas reconhecem os limites que o espaço físico acarreta. Outro conflito que deve ser considerado é a negligencia no momento do parto, que por vezes é realizado dentro da própria prisão, anulando o direito dessa mulher de ter uma atenção especial a ela e a seu filho.

Como já expresso, além dos cuidados hospitalares e médico, a mulher em situação de cárcere necessita de outros olhares, vindos de outros saberes, ou de outros dispositivos. Neste contexto, se faz urgente o olhar da Psicologia.

\section{Críticas ao fazer violento da Psicologia}

A Psicologia se construiu durante muitos anos e se mantém ainda em alguns contextos com um enfoque individualista, "não prestando atenção às determinações históricas nem tampouco à dimensão política da constituição do ser humano" (Azêredo, 2002, p.15). Esse enfoque construiu um olhar elitizado dentro das práticas Psi, olhar esse que desconsiderou e ainda desconsidera as múltiplas formas de estar no mundo.

O profissional Psi ao adentrar as instituições totais deverá engajar-se em um processo politizado, agenciando "territórios de existência que possibilitem a constituição de subjetividades singularizadas" (Furlan; Pelissari, 2013, p. 31). Ao negar esses agenciamentos o profissional Psi fecha os olhos para o sujeito e reproduz técnicas já existentes dentro dessas instituições: a morte desse corpo e a construção da docilidade. Evidencia-se o abuso de poder da ciência Psi que ao legitimar suas técnicas identifica as mulheres em situação de cárcere como inferiores, desumanas, as violentando em atividades sem ética, ao afirmar e reafirmar a classificação, a segregação e a estigmatização dessa mulher.

"Que os tecnicistas nos perdoem, mas a crítica é fundamental" (Patto, 2012, p. 16), a Psicologia precisa abandonar suas teorias ideológicas, que apenas reproduzem as mazelas de uma sociedade desigual e violenta (Patto, 2012).

Até onde vai o cinismo da Psicologia? Ao realizarmos tal questionamento inevitavelmente iremos adentrar num campo de conhecimento por nós produzido, que muitas vezes acabará findando numa miséria, capaz de invisibilizar vidas. A Psicologia poderá ser cúmplice do sistema que produz o abuso do poder e silencia corpos que necessitam de voz.

Compete refletir se os trabalhos da Psicologia estão cumprindo seu papel de potencializar vidas ou apenas facultando a indiferença socialmente generalizada de olhar os indivíduos pelas consequências de suas ações. Refletir principalmente se o trabalho junto com mulheres gestantes em situação de cárcere, tem as empoderado a lutarem pelos seus direitos ou apenas as têm emudecido? Pensar em práticas inovadoras com esses corpos em evidência, é pensar em uma Psicologia que não abandona suas técnicas, mas que junto com elas constrói um olhar de criticidade. Afinal, ao abandonar aquilo que fundamenta a teoricamente, a Psicologia pode cair atrelada a pensamentos do senso comum, mas ao abandonar a crítica, o técnico mantém-se no cinismo da profissão. Cinismo que impossibilita ver além das algemas tecnicistas, de repressão e docilização, que dificulta a empatia com o sofrimento do outro e com suas potencialidades que precisam ser colocadas em evidência.

Alguns profissionais Psi podem estar sendo igualmente responsáveis pelo estado doentio que constrói e sustenta a Psicologia na contemporaneidade. Doentio por manter-se no comodismo, da reprodução de práticas que impedem qualquer tipo de olhar além dos 
juízos de valores já construídos e fixados aos corpos que trabalha. Mantém-se nos discursos de saber com soberba de poder, transformando seu conhecimento em verdades que desrespeitam os direitos humanos.

Ao olhar esses discursos, uma indagação entra em cena, até onde o profissional tem ingenuidade de sua postura cínica? Até onde estão trabalhando propositalmente para atingir suas satisfações de controle sobre os outros? De algum modo, o cínico sabe de sua postura, mas mantém-se em posição de alienação. "Diante da posição cínica da subjetividade contemporânea a crítica e o esclarecimento se tornam impotentes e insuficientes" (Patto, 2012, p. 159). O profissional Psi quando sai do campo individualista e apenas tecnicista passa a também ser criticado, mas cabe a Psicologia produzir conhecimentos para desmascarar a deformação do sujeito na contemporaneidade.

Espera-se que a Psicologia favoreça a liberdade daqueles corpos que ela atravessa, mas quando essa ciência é transformada em opressão se torna incapaz de construir um mundo livre e diferente, fortalecendo as amarras sociais já existentes. Tentar denunciar o lado obsceno dessa Psicologia vai além de apenas criticar, é tentar fazer o novo, movimentar-se além da reprodução de posturas da sociedade atual, composta por inúmeras regras que promovem a barbárie contra aqueles que são considerados corpos fracos. O desencanto, por vezes, permeia os profissionais Psi, tornando esses sujeitos vazios de possibilidades, de estratégias, vazios de vontade de tentarem o novo, de possibilitarem o devir daqueles corpos que necessitam de seus olhares.

Parece impossível a Psicologia sair do desencantamento que a atravessa, mas o impossível, o improvável também faz parte dessa ciência. Um improvável construído por uma dialética entre as teorias Psi e a política. De acordo com Arendt (1998) a política é a liberdade, é o esperar milagres, pois enquanto os homens podem agir, estão em condições de fazer o novo, o improvável, o diferente. Engajados política e eticamente pela emancipação e direitos a todos os que dele deveriam usufruir, é possibilitar um corpo com voz, é oferecer condições que favorecem processos emancipatórios que escampem dos enfadonhos marcadores sociais os quais lançam mão de seus discursos e dispositivos para minimizar a capacidade de subjetivar-se do indivíduo.

\section{Últimas inquietações}

Ao pensar em instituições totais, ou instituições disciplinares reconhece que são territórios propícios para a privação e mortificação dos corpos que nelas estão. Esses ambientes são aparelhos de destituição dos desejos e dos direitos humanos, que promove uma invisibilidade. Estudar gênero é perceber que o corpo feminino é atravessado culturalmente por diversas linhas de construção que o colocam em um território reduzido de passividade e invisibilidade. Invisibilidade maior quando se fala do corpo feminino, gestante e em situação de cárcere.

Diversos saberes produzem discursos que teoricamente viabilizam direitos a essas mulheres, mas na prática, muito desses saberes que se intitulam ciências humanas, nada mais estão fazendo do que manter o poder verticalizado de desculturamento e docilização dos corpos pelas instituições totais e disciplinares.

Percebe-se que essas ciências se preocupam mais em manter seus discursos que produzem poder e dão forças as ações das instituições do que com os corpos femininos supliciados. De acordo com Foucault (2004) o suplício é parte de um ritual, que produz 
sofrimento capaz de hierarquizar. Para a vítima o suplício deve ser marcante, tornando-a infame, e para o poder que o impõe, é ostentado como um triunfo. Triunfo de quem?

De um Estado hipócrita, que em seus discursos desconexos produzem leis, mas não viabilizam que elas sejam efetivadas. Por trás o que prevalece são seus interesses mesquinhos de manutenção de sistemas de carceragem falidos que produzem a morte dos corpos. Corpos esses, que já vinham atravessados por um processo de mortificação e de exclusão pela negligencia das demais instituições falidas, como, a saúde, educação, o saneamento básico, entre outros. Coimbra, Lobo e Nascimento (2009) problematiza que os direitos, atributos universais são construídos historicamente e de uma forma não tão grandiosa, os quais por diversos saberes científicos etiquetam quais humanos são dignos aos direitos humanos.

Ao adentrar o cárcere feminino os profissionais depararam-se com inúmeros desafios e barreiras enrijecidas que poderão ser desvencilhadas por práticas reflexivas e políticas capazes de romper com a hipocrisia do Estado e das instituições. Os profissionais devem, não apenas defender os direitos das mulheres em situação de cárcere, mas afirmálas como sujeitos de direitos e transformá-las em potências criativas, capazes de recriar a si e seus modos de viver.

Basta aos profissionais refletirem se eles querem continuar sendo corpos dóceis, cínicos e hipócritas que reproduzem padrões impostos, ou quebrarem barreiras visíveis e invisíveis, recriando-se para que além de terem voz, darem voz aos inaudíveis. Atravessar aqueles corpos que não são considerados humanos, e construir com eles possibilidades de se colocarem como tais.

Para isso, é preciso fazer o improvável acontecer, o impossível, mas que graça teria as ciências se não procurassem a utopia? Do criar o lugar que ainda não existe, além da fantasia e do imaginário. É dar asas a esses sonhos de fazer no irrealizável algo novo acontecer, não somente para as mulheres em situação de maternidade em cárcere, mas com elas.

\section{Referências}

Arendt, H. (1998). 0 que é política. Rio de Janeiro: Bertrand Brasil.

Azêredo, S. M. M.(2002). O político, o público e a alteridade como desafio para a Psicologia. Psicologia Ciência e Profissão. 22(4), 14-23.

Badinter, E. (1985). Um amor conquistado: o mito do amor materno. (W. Dutra, Trad.). Rio de Janeiro: Nova Fronteira.

Borges, L.S. et al. (2013). Abordagens de gênero e sexualidade na Psicologia: revendo conceitos, repensando práticas. Psicologia: ciência e profissão, 33(3), 730-745. 
Butler, J. (2010). Problemas de gênero: feminismo e subversão da identidade. (3a ed.) (R Aguiar, Trad.). Rio de Janeiro: Civilização Brasileira.

Coimbra, C. M. B.; Lobo, L. F.; Nascimento, M. L. (2009). A invenção do humano como modo de assujeitamento. Política e afetividade.

Conselho Nacional de Justiça (CNJ/Brasil). (2011). Cartilha da Mulher Encarcerada. Poder Judiciário, Brasília, DF.

Constituição da República Federativa do Brasil: promulgada em 8 de outubro de 1988 (2003 -1988, 8 de outubro). (8a ed.). São Paulo: Revista dos Tribunais.

Deleuze, G., \& Guattari, F. (1995). Mil Platôs 1: Capitalismo e Esquizofrenia. Rio de Janeiro: Ed. 34.

Deleuze, G., \& Guattari, F. (1996). Mil Platôs 3: Capitalismos e Esquizofrenia. São Paulo: Ed. 34.

Espinoza, O. (2004). A mulher encarcerada em face do poder punitivo. São Paulo: IBCCRIM.

Foucault, M. (1988). História da Sexualidade I: A vontade de saber. (M. T. C. Albuquerque, Trad.). Rio de Janeiro: Graal.

Foucault, M. (1984). História da Sexualidade II: O uso dos prazeres. (M. T. C. Albuquerque, Trad.). Rio de Janeiro: Graal.

Foucault, M. (1985). História da Sexualidade III: 0 cuidado de si. (M. T. C. Albuquerque, Trad.). São Paulo: Graal.

Foucault, M. (1982). Microfísica do poder (13a. ed.). Rio de Janeiro: Graal.

Foucault, M. (1997). Resumo dos Cursos do Collège de France 1970-1982. Rio de Janeiro: Jorge Zahar Editor. 
Foucault, M. (2004). Vigiar e punir: nascimento da prisão (28a ed.). Petrópolis: Vozes.

Furlan, V.; Pelissari, M. A. (2013). Psicologia e os contextos Sócio-Político-Cultural e as Políticas Sociais no século XXI. Psicologia Ciência e Profissão. 33, 24-31.

Goffman, E. (1987). Manicômios, prisões e conventos (2a ed.). São Paulo: Perspectiva.

Lei no 8.069/90, de 13 de julho de 1990 (1990, 13 de julho). Dispõe sobre o Estatuto da Criança e do Adolescente e dá outras providências. Brasília, DF: Presidência da República: Casa Civil. Subchefia para Assuntos Jurídicos. Recuperado em 13 de outubro de 2015, de http://www.planalto.gov.br/ccivil_03/LEIS/L8069.htm.

Lei no 7.210, de 11 de julho de 1984 (1984, 11 de julho). Institui a Lei de Execução Penal. Diário Oficial [D.0] República Federativa do Brasil, Brasília, DF.

Lei no 11.942, de 28 de maio de 2009 (2009, 28 de maio). Dá nova redação aos Arts. 14, 83 e 89 da Lei no 7.210, de 11 de Julho de 1984. - Lei de Execução Penal, para assegurar às mães presas e aos recém-nascidos condições mínimas de assistência. Diário Oficial [D.O] República Federativa do Brasil, DF.

Louro, G.L. (1997). Gênero, sexualidade e educação. Petrópolis: Vozes.

Louro, G. L. (2004). Um corpo estranho: Ensaios sobre sexualidade e teoria queer. Belo Horizonte: Autêntica.

Miyamoto, Y.; Krohling, A. (2012, janeiro/junho). Sistema prisional brasileiro sob a perspectiva de gênero: invisibilidade e desigualdade social da mulher encarcerada. Direito, Estado e Sociedade, Rio de Janeiro, 40, 223-241.

Ormeño, G. I. R. (2013). Histórico familiar de mulheres encarceradas: fatores de risco e proteção para os filhos. Tese Doutorado, Universidade Federal de São Carlos, São Carlos. 
Patto, M. H. S. (2012). Formação de psicólogos e relações de poder: Sobre a miséria da Psicologia. São Paulo: Casa psi Livraria e Editora Ltda.

Portaria Interministerial de 1 de janeiro de 2014 (2014, 01 de janeiro). Institui a Política Nacional de Atenção Integrá-la Saúde das Pessoas Privadas de Liberdade no Sistema Prisional (PNAISP) no âmbito do Sistema Único de Saúde (SUS). Brasília, DF: Ministério da Saúde, Conselho Nacional de Saúde.

Rita, R.P.S. (2006). Mães E crianças atrás das grades: em questão o princípio da dignidade da pessoa humana. Dissertação de Mestrado, Universidade de Brasília, Brasília.

Saffioti, H. I. B. (1997). 0 poder do macho (9a ed.). São Paulo: Editora Moderna.

Recebido / Received: 20/09/2015

Aprovado / Approved: 14/12/2015 